\title{
INCORPORAÇÃO DA FIBRA DO BAGAÇO DE CANA-DE- AÇÚCAR NO CIMENTO
}

\author{
F. G. ROSSI ${ }^{1}$, J. MARTINS ${ }^{2}$, M. DENARI ${ }^{2}$, H. HASSAINE ${ }^{2}$, T. GREGÓRIO ${ }^{2}$, C. E. N. REIS ${ }^{2}$, \\ ${ }^{1}$ Centro Universitário da FEI, Departamento de Engenharia Química \\ ${ }^{2}$ Centro Universitário da FEI \\ E-mail para contato: fernandagrossi@ hotmail.com
}

\begin{abstract}
RESUMO - Diante ao grande problema de fibras do bagaço de cana-de-açúcar em excesso, provenientes da produção do etanol e açúcar, sendo este um dos maiores setores de produção nacional, nota-se a viabilidade da incorporação deste resíduo ao cimento, possibilitando seu uso na construção civil, que é um dos setores em maior crescimento no país. Com esta incorporação, pretende-se fornecer uma melhoria nas propriedades mecânicas, substituindo, por exemplo, o amianto, que hoje é utilizado como matéria prima da indústria civil. Além disso, esta fibra mineral já é proibida em alguns países por ser prejudicial à saúde, sendo este mais um motivo favorável à realização do trabalho. Por estas razões, desenvolveu-se um estudo onde foi testada a incorporação de diferentes concentrações de fibras na presença ou ausência de antraquinona. Foram realizados testes de resistência à compressão, à tração por compressão diametral, à tração por flexão e absorção de água, devido à estrutura presente no laboratório e uma maior abrangência dos resultados. Ao comparar os resultados obtidos com o cimento puro, verificou-se que com a incorporação da fibra, houve uma redução na resistência à compressão e um aumento na resistência à tração por flexão. Quando comparado com telhas constituídas por cimento e amianto, apesar da utilização de diferentes corpos de provas, pode-se dizer que os resultados obtidos nos testes de resistência à tração na flexão e absorção de água foram satisfatórios.
\end{abstract}

\section{INTRODUÇÃO}

O Brasil é um país que ainda sofre com a falta de energia e moradias para grande parte de sua população. Para minimizar a falta de energia, temos investido muito na geração a partir de fontes renováveis, como a produção de álcool etanol a partir da cana-de-açúcar, por exemplo. (Savastano, 2003) Porém, a cultura da cana no país foi introduzida sem a devida preocupação com o destino dos subprodutos. O resíduo obtido em maior quantidade é o bagaço de cana, sendo que o bagaço corresponde a 1/3 do total da cana-de-açúcar (Unica, 2012).

Em paralelo a isso, os altos custos dos materiais de construção e mão-de-obra vêm dificultando o crescimento do setor da construção civil. Outro fator importante é a questão 
ambiental, pois a extração dos agregados naturais, como brita, areia e amianto, geram uma agressão irreparável ao meio ambiente. Assim, muitos setores da sociedade, públicos e privados, vem se mobilizando em busca de soluções para baratear este desenvolvimento e minimizar os efeitos ambientais.

Unindo os dois problemas em uma solução, foi proposta a utilização de parte dos resíduos gerados a partir da cana na produção de fibrocimento destinado à construção civil a fim de atender à crescente demanda de produtos mais eficientes, econômicos e sustentáveis (Savastano, 2003)

\subsection{Fibrocimento}

O fibrocimento consiste de uma base de cimento que apresenta ao longo de sua matriz fibras distribuídas, que podem ser de origem mineral, sintética ou ainda vegetal, destinadas a conferir resistência à tração (Artigas, 2013). A utilização dessas fibras torna o cimento mais sustentável quando comparado ao cimento comum, sendo menos agressivo ao meio ambiente, pois reduz o consumo de fibras derivadas do petróleo, é isento de amianto e aumenta a capacidade de isolamento acústico, além de possuir aplicação simples, rápida e de baixo custo (Caldas, 2002).

\subsection{Amianto}

O amianto, também conhecido como asbesto, é uma fibra mineral sedosa extraída de rochas compostas de silicatos hidratados de magnésio, e apresenta-se em abundância na natureza sob duas formas: serpentinas (amianto branco) e anfibólios (amianto azul e marrom). (ABREA, 2011). É um material que apresenta diversas características interessantes, como alta resistência à tração, não oxida, possui grande durabilidade e flexibilidade, afinidade ao cimento, por isso é muito aplicado na construção civil (pisos vinílicos, telhas, caixas d’água, divisórias, forros falsos, tubulações, vasos de decoração, entre outros artefatos de cimento-amianto), isolamento acústico ou térmico, e nas indústria bélica, aeroespacial, têxtil, de papel e papelão, naval entre outras aplicações.

Apesar disso e de apresentar um baixo custo de exploração, a exposição ao amianto está relacionada à ocorrência de diversas patologias sendo classificado pela Agência Internacional de Pesquisa (IARC) no grupo dos reconhecidamente cancerígenos para os seres humanos. O amianto branco é usado na indústria da construção civil nos países em desenvolvimento, como o Brasil, mas é proibida na maioria dos países industrializados como EUA e países da Europa. Já o amianto, o azul e o marrom, são proibidos em todo o mundo (INCA, 2013).

\subsection{Bagaço de Cana-de-Açúcar}

A grande vantagem do bagaço de cana é sua abundância. Estima-se que para cada tonelada 


\section{9 a 22 de outubro de 2014 \\ Florianópolis/SC}

de cana-de-açúcar processada, tem-se a produção de $276 \mathrm{~kg}$ de bagaço (Jank, 2009). Só na safra de 2012/2013, foram estimadas 509 milhões de toneladas de cana processadas. O bagaço de cana, além de outras coisas, é composto por polímeros naturais como celulose, hemicelulose e lignina. A celulose é o principal componente da parede celular que também apresenta quantidades relevantes de lignina, outro polímero natural que é caracterizada por apresentar um grau de polimerização baixo que por sua vez, reduzem a resistência mecânica do material. Além disso, a fibra possui característica hidrofílica e, portanto, absorve água. É necessário que esse aspecto seja neutralizado para que haja a incorporação da fibra na matriz, já que quanto mais água o compósito absorver, menor será sua resistência.

Ainda segundo Jank (2009), a pré-lavagem do bagaço de cana-de-açúcar mais eficaz foi aquela que usou soluções de silicato de sódio a $5 \%$ e sulfato de alumínio $30 \%$, que proporcionaram uma redução na absorção de água de $50 \%$ a $60 \%$, além de conferir uma melhor "mineralização" proporcionando maior proteção da fibra no meio alcalino.

\subsection{Antraquinona}

Além dos pré-tratamentos químicos, foi utilizada a antraquinona antes de realizar a incorporação à matriz de cimento, com o objetivo de potencializar a proteção da fibra em meio alcalino. Segundo Rossi (2012), a antraquinona faz com que a Energia de Ativação seja aumentada, e, como essa energia constitui a barreira necessária para que a reação tenha início, quanto mais alta a energia de ativação, mais estável é a amostra, por ser dificultada a reação de quebra e consequente degradação das fibras.

\section{MATERIAIS E MÉTODOS}

O bagaço de cana-de-açúcar utilizado neste trabalho foi gentilmente cedido pela ROSA Indústria e Comércio de Produtos Agrícolas, CNPJ: 45483054/0001.93, na forma de fibras secas e limpas. Na própria indústria, após a utilização da cana no processo, o bagaço já foi submetido a lavagens a vapor e previamente triturado.

\subsection{Determinação da quantidade de açúcares presentes na fibra}

A quantidade de açúcar livre presente nas fibras foi determinada utilizando o método DNS com o objetivo de determinar a quantidade de açúcar presente na fibra. No preparo das amostras, foram pesados $10 \mathrm{~g}$ de bagaço e colocados em contato com $150 \mathrm{~mL}$ de água destilada em um processo de refluxo durante uma hora. Após filtração simples, adicionou-se ao filtrado, $1 \mathrm{~mL}$ da amostra com 1,5 mL de DNS, agitou-se e a solução que foi submetida a um banho de água fervente durante 5 minutos. Posteriormente a amostra foi resfriada até a temperatura ambiente e seu volume foi completado para $25 \mathrm{~mL}$ em tubos aferidos com água destilada. Realizou-se então a leitura da absorbância em um espectrofotômetro ultravioleta digital microprocessado da marca Quimis, modelo Q798U, a $540 \mathrm{~nm}$.

\subsection{Tratamento químico do bagaço de cana-de-açúcar}


Visando a imobilização da matéria orgânica constituinte e a diminuição da capacidade de absorção de água, realizou-se um tratamento químico a base de silicato de sódio em combinação com sulfato de alumínio. Uma parte das fibras após secagem foi então impregnada com antraquinona misturada à vaselina para que formasse um material líquido possibilitando a mistura à fibra.

\subsection{Preparação do compósito de cimento}

Para a produção da matriz foi utilizada a relação mássica de 1:2 entre o cimento e areia, e uma quantidade de água igual a $30 \%$ em relação ao volume do corpo de prova utilizado. As quantidades de fibra de bagaço de cana utilizadas foram $1 \%$ e $5 \%$ do volume total do bloco de concreto. Os materiais foram misturados em argamasseiras e colocados em moldes de acordo com as normas vigentes para verificação das propriedades mecânicas

\subsection{Análise das propriedades mecânicas}

Os compósitos foram testados em relação à resistência à compressão (NORMA ABNT NBR 5739:2007), resistência à tração por compressão diametral (NORMA ABNT NBR 7222:2010), resistência à tração por flexão (NORMA ABNT NBR 12142:2010) e absorção de água (NORMA ABNT NBR 12118:2011)

\subsection{Planejamento Experimental}

Foi realizado um planejamento fatorial $2^{2}$ para estudar a influência das diferentes porcentagens de fibra de bagaço de cana na presença e ausência de antraquinona.. Os ensaios foram repetidos cinco vezes obtendo-se assim 100 ensaios. As variáveis dependentes correspondentes às respostas foram: resistência à compressão, resistência à tração por compressão diametral, resistência à tração porflexão e absorção de água. Os valores das variáveis independentes, porcentagem de fibra de bagaço de cana e concentração de antraquinona são mostrados na Tabela 1.

Tabela 1 - Planejamento fatorial $2^{2}$ e análise das variáveis independentes

\begin{tabular}{|c|c|c|}
\hline & \multicolumn{2}{|c|}{ Variáveis Reais e Codificadas } \\
\hline & $\begin{array}{l}\text { Concentração Antraquinona } \\
\text { AQ (\%) }\end{array}$ & $\begin{array}{l}\text { Porcentagem de Fibra de Bagaço } \\
(\%)\end{array}$ \\
\hline 1 & $0(-1)$ & $1(-1)$ \\
\hline 2 & $1(+1)$ & $1(-1)$ \\
\hline 3 & $0(-1)$ & $5(+1)$ \\
\hline 4 & $1(+1)$ & $3(+1)$ \\
\hline PC & $0,5(0)$ & $3(0)$ \\
\hline
\end{tabular}

Para o planejamento fatorial $2^{2}$, as curvas de superfície de resposta foram obtidas a partir 
de polinômios ortogonais resultantes da matriz do arranjo ortogonal, que combina os níveis codificados entre si, estabelecendo uma relação de dependência entre eles, e então foram ajustados em função das variáveis independentes investigadas. Os dados experimentais foram tratados com o auxílio do programa comercial STATISTICS 7.1 (Calado et al., 2003).

\section{RESULTADOS E DISCUSSÃO}

\subsection{Análise da quantidade de açúcar presente na fibra}

A análise da quantidade de açúcar presente na amostra em solução apresentou uma concentração de $0,46 \mathrm{~g} / \mathrm{L}$ de açúcares livres e consequentemente uma porcentagem em massa de 0,69\%. Devido à baixa concentração de açúcar presente optou-se por não realizar a primeira etapa de lavagem com água quente, presente no plano de trabalho anteriormente apresentado.

\subsection{Preparação do compósito de cimento}

Foram preparados todos os 75 corpos de provas cilíndricos e os 25 corpos de provas prismáticos, conforme as imagens mostradas na Figura 1.
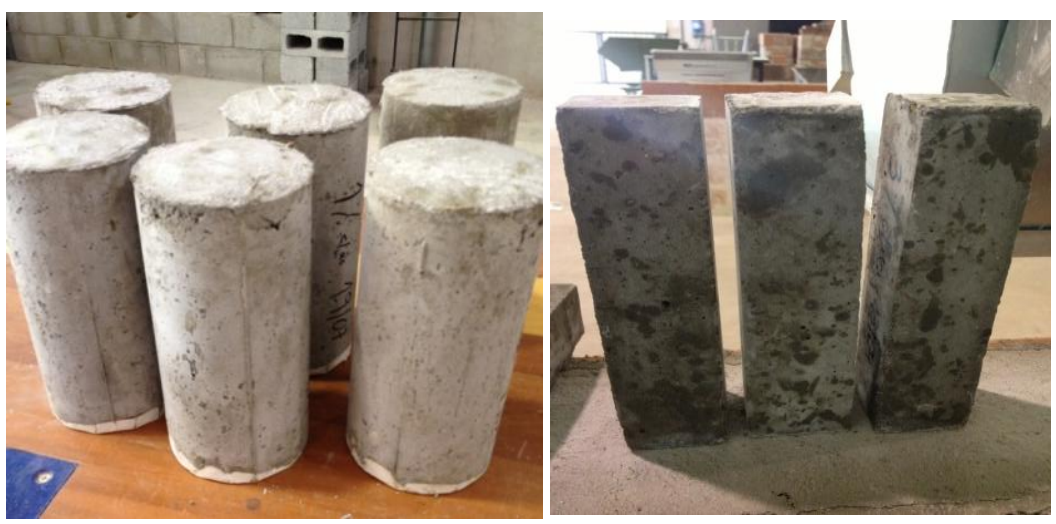

Figura 1 - Corpos de Provas Cilíndricos e Prismáticos

\subsection{Análise das propriedades mecânicas}

Os corpos de provas preparados foram testados em relação à resistência à compressão, resistência à tração por compressão diametral, resistência à tração por flexão e em relação à absorção de água. A partir dos dados obtidos experimentalmente, com auxílio do planejamento experimental $2^{2}$, pôde-se verificar quais foram as variáveis mais significativas em cada propriedade estudada e as interações entre elas, obtendo a melhor condição para cada teste.

Tratamento Estatístico para a Resistência à Compressão: De acordo com o polinômio ortogonal obtido representado pela Equação 1, observou-se no caso da resistência à compressão, que tanto a concentração de fibra utilizada $\left(X_{1}\right)$, quanto a presença de antraquinona $\left(X_{2}\right)$ foram variáveis significativas e portanto interferem nos resultados. 


$$
Y=22,6-6,03( \pm 1,12) \cdot X_{1}-2,87( \pm 1,12) \cdot X_{2}
$$

A Figura 2, construída a partir do polinômio ortogonal, mostra que para os limites inferiores de concentração de fibra (1\%) e de antraquinona (0\%), os valores de resistência aumentaram. Desta forma, podemos afirmar que para a resistência à compressão, a melhor condição encontrada foi na ausência de antraquinona e com uma concentração mínima de fibra, igual a $1 \%$.

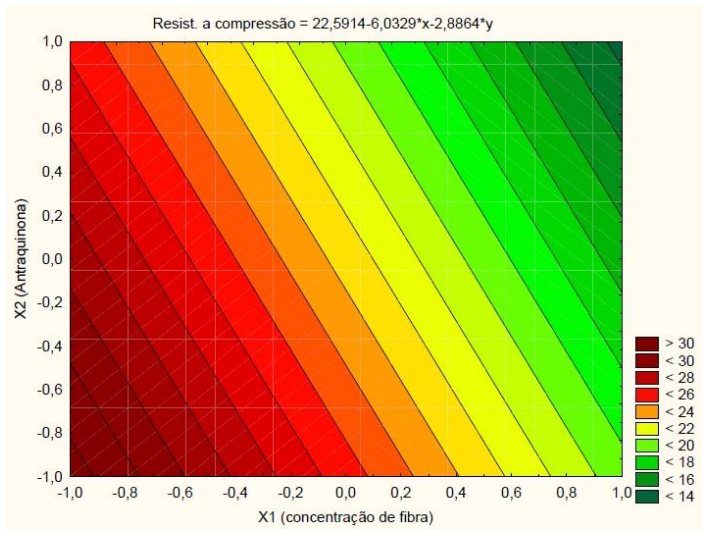

Figura 2 - Curva de Contorno obtida para a resistência à compressão em função das concentrações de antraquinona e fibra de bagaço de cana.

Tratamento Estatístico para Resistência à Tração por Compressão Diametral : De acordo com o polinômio ortogonal obtido representado pela Equação 2, pôde-se perceber que somente a concentração de fibra $\left(\mathrm{X}_{1}\right)$ e a interação entre esta e a presença de antraquinona $\left(\mathrm{X}_{1} \cdot \mathrm{X}_{2}\right)$ são significativos na análise.

$$
Y=1,53-0,58( \pm 0,09) \cdot X_{1}-0,19( \pm 0,09) \cdot X_{1} \cdot X_{2}
$$

A Figura 3, construída a partir do polinômio ortogonal, mostra que a melhor condição de resistência à tração por compressão diametral foi alcançada com a menor concentração de fibra (1\%) e a maior concentração de antraquinona (1\%).

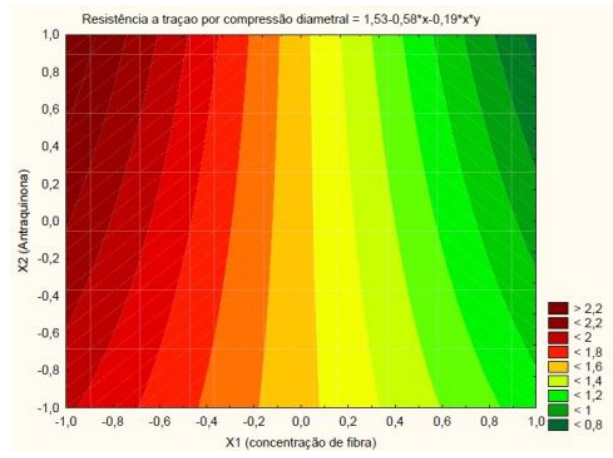


Figura 3 - Curva de Contorno obtida para a resistência à tração por compressão diametral em função das concentrações de antraquinona e fibra de bagaço de cana.

Tratamento Estatístico para Resistência à Tração na Flexão: Para os resultados do teste de resistência à tração na flexão pôde-se perceber de acordo com a Equação 3, que somente a concentração de antraquinona $\left(\mathrm{X}_{2}\right)$ se mostrou como variável significativa. Dentre os níveis de antraquinona estudados, nota-se que quanto menos antraquinona, maior a resistência, isto é, os melhores resultados foram obtidos na ausência de antraquinona.

$$
Y=9,09-1,05( \pm 0,27) \cdot X_{2}
$$

Tratamento Estatístico para o teste de absorção de água: Os resultados do teste de absorção de água analisados de acordo com o polinômio ortogonal obtido e representado pela equação 4, mostraram que, somente a concentração de fibra de bagaço de cana (X1) foi considerada como variável significativa.

$$
Y=10,01+1,60( \pm 0,21) \cdot X_{1}
$$

De acordo com o polinômio acima, quanto maior a concentração de fibra, maior o valor da absorção de água. Logo, a condição que garante menor absorção pode ser alcançada utilizando o limite inferior para a concentração de fibra (1\%) e na ausência de antraquinona.

Considerando todos os tratamentos estatísticos realizados, as melhores condições encontradas para cada teste podem ser verificadas na tabela 2.

Tabela 2 - Resumo das melhores condições de cada teste realizado

\begin{tabular}{|l|c|c|}
\hline & $\begin{array}{l}\text { Concentração de fibra } \\
\text { (X1) }\end{array}$ & $\begin{array}{l}\text { Concentração de } \\
\text { antraquinona (X2) }\end{array}$ \\
\hline Resistência à compressão & $1 \%$ & $0 \%$ \\
\hline $\begin{array}{l}\text { Resistência à tração por } \\
\text { compressão diametral }\end{array}$ & $1 \%$ & $1 \%$ \\
\hline Resistência à tração na flexão & - & $0 \%$ \\
\hline Absorção de água & $1 \%$ & - \\
\hline
\end{tabular}

\section{CONCLUSÃO}

A partir da discussão dos resultados, nota-se que com o aumento da fração percentual de fibra tratada incorporada no cimento, tem-se uma redução da resistência à compressão, da resistência à compressão diametral resistência à tração por flexão e também torna o fibrocimento mais suscetível à absorção de água. Portanto, altas concentrações de fibra não atuam como material de reforço do fibrocimento. Em relação à antraquinona dispersa em vaselina, não houve influência na resistência à tração por compressão diametral, contudo, notou-se uma atuação 


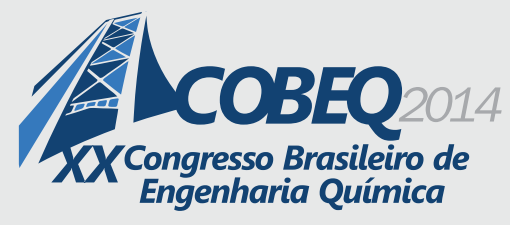

19 a 22 de outubro de 2014

Florianópolis/SC

redutora na resistência à compressão e na tração por flexão nos corpos de prova mas essas variações foram minimizadas quando utilizou-se um menor teor de fibras. A respeito do teste de absorção de água, a diferença entre os resultados diminuiu com a utilização em níveis baixos de antraquinona e fibra. Comparando os resultados com valores empíricos encontrados na literatura, pode-se comprovar a hipótese de que a mistura fibras e antraquinona, nas quantidades utilizadas, não aumenta a resistência à compressão do cimento. Como intuito inicial do trabalho foi a substituição da fibra de amianto pela fibra do bagaço de cana-de-açúcar e, atualmente, o mesmo é ainda muito utilizado na fabriação de telhas, pode-se fazer as comparações para os testes de absorção de água e resistência à flexão nas mesmas. Para a absorção de água, o valor máximo aceitável em telhas chega à $37 \%$, enquanto que os resultados obtidos chegam a um valor experimental de aproximadamente $11 \%$. Já em relação à resistência à flexão, os corpos de prova utilizados para o teste específico da telha possuem dimensões diferentes das utilizadas no trabalho, o que impede uma comparação direta. Porém, como base de comparação, quanto à ordem de grandeza, os resultados apresentados no trabalho seguem a mesma lógica de valor do que àqueles encontrados na literatura. Por fim, é importante ressaltar que estes valores de comparação são empíricos e encontrados na literatura a partir de experimentos anteriores. Também deve-se estar atento à aplicação do fibrocimento, isto é, para cada aplicação são exigidos testes específicos a serem realizados.

\section{REFERÊNCIAS}

ARTIGAS, L. V., Fibrocimento: Materiais de construção III, Universidade Federal do Paraná UFPR. Curitiba, 2013.

ASSOCIAÇÃO BRASILEIRA DOS EXPOSTOS AO AMIANTO, Amianto ou Asbesto. Disponível em: <http://www.abrea.com.br/02amianto.htm>.

CALADO, V.; MONTGOMERY, D. C.; Planejamento de Experimentos usando o Statistica. Rio de Janeiro: E-Papers, 2003, 260p.

CALDAS, A. S.; Estudo da durabilidade de compósitos reforçados com fibras de celulose Departamento de Engenharia de Construção Civil da USP. São Paulo, 2002.

INSTITUTO NACIONAL DO CÂNCER, Doenças relacionadas à exposição ao amianto. Disponível em: <http://www.inca.gov.br/conteudo_view.asp.id=15>.

JANK, M. S., A competitividade do etanol brasileiro. 2009. Disponível em: $<$ http://www.senado.gov.br/sf/comissoes/ci/ap/AP20090831_Comissao_Infraestrutura_Marcos\% 20_Jank_(res).pdf $>$.

ROSSI, F.G. Análise dos processos de polpação do bagaço de cana-de-açucar: estudo termocinético da influência da antraquinona no tratamento alcalino. Tese (Doutorado em Engenharia Química) - Faculdade de Engenharia Química. Universidade Estadual de Campinas, Campinas, 2012.

SAVASTANO, Jr., WARDEN, P. G. Special theme issue: Natural fibre reinforced cement composites. Cement\& Concrete Composites, v.25, n.5, p.517-624, 2003.

UNIÃO DAS INDÚSTRIAS DE CANA-DE-AÇÚCAR, Revisão de safra - 2012/2013. São Paulo, 2012. Setor Sucroenergético, 2012. Disponível em: 〈http://www.unica.com.br〉. 